\title{
Stacking efficiency of terrestrial Plant-Microbial Fuel Cells growing Ocimum basilicum and Origanum vulgare
}

\author{
Kristopher Ray S. Pamintuan ${ }^{1,2, *}$, Arnie Jantzen G. Ancheta ${ }^{1}$, and Shaina Marie T. Robles ${ }^{1}$ \\ ${ }^{1}$ School of Chemical, Biological, and Materials Engineering and Sciences, Mapua University, Intramuros, Manila 1002, Philippines \\ ${ }^{2}$ Center for Renewable Bioenergy Research, Mapua University, Intramuros, Manila 1002, Philippines
}

\begin{abstract}
Plant-Microbial Fuel Cells (PMFCs) are an emerging type of renewable energy that generates an electric current through the consumption of rhizodeposits by exoelectrogenic bacteria that lives in the rhizosphere of the plant. Since the plant is not harmed by the energy-harvesting process, PMFC technology has the potential to simultaneously produce food (biomass) and generate electricity. As of now, power densities of PMFCs have remained low and commercialization is not yet possible. To achieve higher power densities, the stacking behaviour of PMFCs needs to be studied. In this study, several cells growing Ocimum basilicum (basil) and Origanum vulgare (oregano) were constructed and evaluated. Upon stacking, it was shown that the constructed PMFCs did indeed behave like batteries, where the voltage of cells connected in series are additive, and that the voltage of cells connected in parallel are constant. The actual values of voltage of stacked cells are similar to the expected value $(\alpha=0.05)$. Cumulative stacking tests revealed that there is no apparent loss in voltage upon stacking up to 9 cells growing $O$. basilicum. Further computation of power and power densities have proven that stacking is a viable method of amplifying electricity generation in PMFCs, as both increased with increasing number of cells connected in series.
\end{abstract}

\section{Introduction}

Electricity plays a key role in the development and advancement of technologies that most people benefit today. It improves way of living through faster and convenient services. Increasing population also increases demand of electricity, thus it is important to find new sources that can supplement the needs of people. With our present aversion to non-renewable electricity sources based on out effort to curb global warming, an attractive alternative source of electricity are Plant-Microbial Fuel Cells.

Plant-Microbial Fuel Cells (PMFCs) are a class of bioelectrochemical systems that utilizes electrogenic bacteria to generate electricity [1]. The electrogenic bacteria is in a mutualistic relationship with the plant wherein the plant excretes rhizodeposits through its roots for the bacteria to feed. This enables a PMFC to continuously generate electricity as long as the plant is alive and photosynthesizing. A beneficial side-effect to this process is that the model plant can be an agriculturally valuable commodity, hence removing the competition between food production and power generation. Theoretically, a maximum power density of $3.2 \mathrm{~W} / \mathrm{m}^{2}$ can be harvested in a PMFC. Past studies show that the power density can be enhanced by choosing the correct plant, and having an efficient design [2-5]. However, due to design and physiological limitations, actual tests on PMFCs show that the current designs and configurations tested are still a long way from achieving commercially-viable electricity levels [6]. Stacking and compartmentalization can be used to solve this dilemma.

In stacking, multiple cells are connected together in series, parallel, or a combination of both to achieve a desired voltage and current. A previous study has investigated the validity of stacking in aquatic PMFCs [7]. The researchers found that in stacks of three cells, voltage and current were increased roughly three times that of an individual, confirming the validity of stacking. In microbial fuel cells (MFC), several reports also noted that stacking rules apply [8-10]. However, these studies only utilized a small number of cells.

PMFCs, being bioelectrochemical systems, may not achieve full stacking potential if connected in large numbers. Thus, this study aims to determine the stacking efficiency of a PMFC growing two types of plants: Ocimum basilicum (basil) and Origanum vulgare (oregano). The effect of series and parallel arrangements to the power density is the main focus, as well as the determination of the apparent loss of potential when many cells are connected to each other.

\section{Methodology}

\subsection{PMFC design and operation}

The batch PMFC designed measured 6 in $\mathrm{x} 6$ in $\mathrm{x} 12$ in $(\mathrm{LxWxH})$ and was made of twin wall polycarbonate. Holes were placed at the bottom for drainage and gas

Corresponding author: krspamintuan@mapua.edu.ph 
exchange. The electrodes used were graphite rods $(2 \mathrm{~mm}$ diameter, $15 \mathrm{~cm}$ long). Cotton cloth spanning the whole cross section ( 6 in $\times 6$ in) was placed 4 inches from the bottom of the container. The cathode was placed 2 inches from the bottom of the container, and the anode was placed 4 inches below the soil surface. The PMFC assembly is shown in Figure 1.

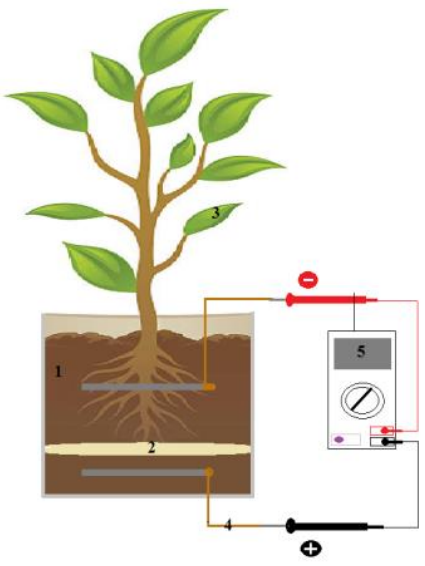

Fig. 1. PMFC assembly; (1) anode, (2) cotton sloth separator, (3) model plant, (4) connecting copper wires, (5) multimeter

25 seeds of Ocimum basilicum were planted in a seed tray using garden soil for 20 days. For Origanum vulgare, small, same-sized cuttings were severed from the mother plant and rooted in moist garden soil for 20 days. After sprouting and growout, the seedlings were transferred to their cells ( 9 cells each, one plant per cell). They were given 10 days to acclimatize to the new container. All plants were watered twice daily with the same amount $(50 \mathrm{~mL})$. The cells were observed for 30 days after acclimatization.

\subsection{Measurement of parameters}

Stacking experiments were designed to explore the limit of series and parallel arrangements on both plants and were based on a previous investigation [7]. Voltage for individual and stacked cells were measured twice a day (7:00 am and 5:00 pm) against 1000 ohms external resistance using a digital multimeter (RS Pro RS14). The cells are arranged in a $3 \times 3$-cell grid for easier stacking. Three cells per trial were stacked together in both series and parallel arrangements for verification (Figure 2). Afterwards, measurements for 9 cells connected in series and parallel were also performed. Cumulative stacking tests were also performed to determine apparent connection loss in voltage for both series and parallel connections.

Soil $\mathrm{pH}$ was monitored using a soil $\mathrm{pH}$ probe. Ambient temperature and relative humidity values were also monitored through a hydrometer with built-in thermometer. Soil $\mathrm{pH}$, temperature, and relative humidity values were monitored to make sure that no extreme conditions are encountered to skew the power generation of the PMFCs.

\subsection{Polarization}

Polarization tests were done by manually changing the value of the external resistor from 10 to $50000 \mathrm{ohms}$ and measuring the voltage across individual and stacked cells. Polarization was done after the $30^{\text {th }}$ day of voltage monitoring and were done in triplicate, with the average values being reported.

\section{Results and discussion}

\subsection{Voltage of individual PMFCs}

Shown in Figure 2 are the comparative voltage readings of $O$. basilicum and $O$. vulgare in the experimental time range. After 2 weeks of fairly constant voltage, PMFCs with $O$. basilicum showed increased voltage, while cells with $O$. vulgare displayed a rather consistent voltage. This may pertain to the status of PMFCs, whether the soil microfauna is already in equilibrium. Though the plants were given 10 days after transplanting to equilibriate, the sudden increase in voltage for cells with $O$. basilicum are indicative that the microorganisms in the rhizosphere are still multiplying in response to an increased amount of rhizodeposits. It is worth noting that at the time range of this study, O. basilicum is still in its foliar development stage while $O$. vulgare is relatively mature, and the differences in stages of development are indicative of the difference in voltages [11]. No extraordinary dips in $\mathrm{pH}$ (more than \pm 1 increment change in a day) and temperature (more than $\pm 10^{\circ} \mathrm{C}$ in a day) were detected, and thus the environment has little to no effect on the voltage. The voltage exhibited by cells growing $O$. basilicum had significantly higher voltage than that of $O$. vulgare $(\alpha=0.05)$.

Variation of voltage with respect to the time of day was observed for cells growing $O$. vulgare. Generally, voltage readings would be higher in the morning and less in the afternoon, presumably due to the differing photosynthetic activity of the plant, although no previous studies have reported such variation. More studies are to be conducted before power generation can be linked with the time of the day.

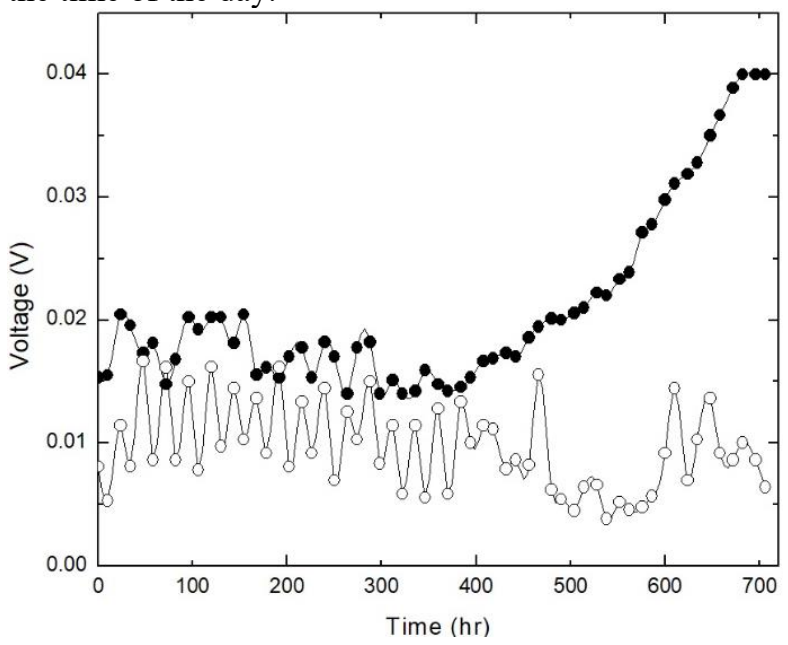

Fig. 2. Average voltage of individual PMFCs growing $O$. basilicum $(\bullet)$ and $O$. vulgare $(\circ)$ 


\subsection{Effect of stacking on voltage}

The voltages of PMFCs growing both plants individually and stacked are shown in Figure 3. For both plants in series arrangement, it was noticed that minor fluctuations in the voltage reading of individual cells lead to amplified disturbances in the voltage of cells connected in series. The effect is more pronounced on 9 cells connected in series, which is expected (Figures $3 a$ and $4 a$ ).

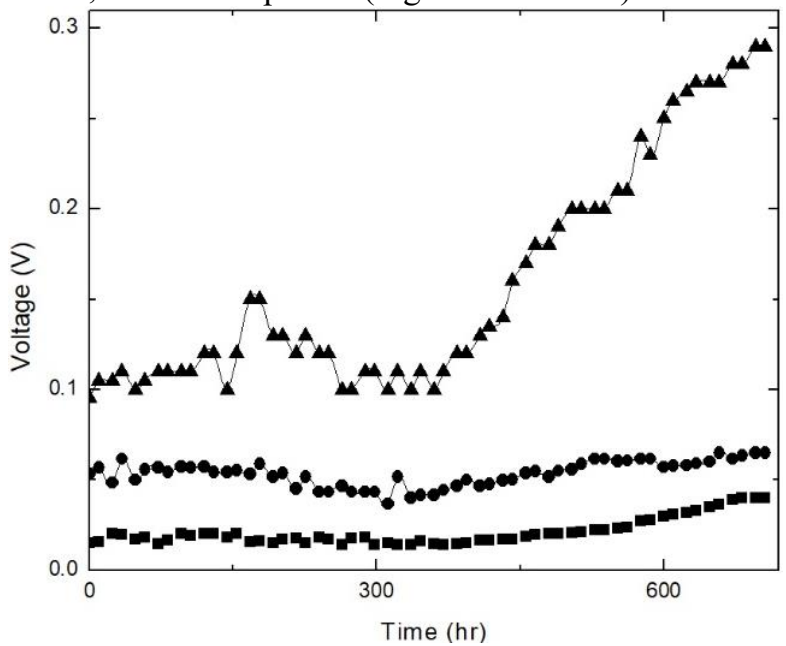

(a) Series connection

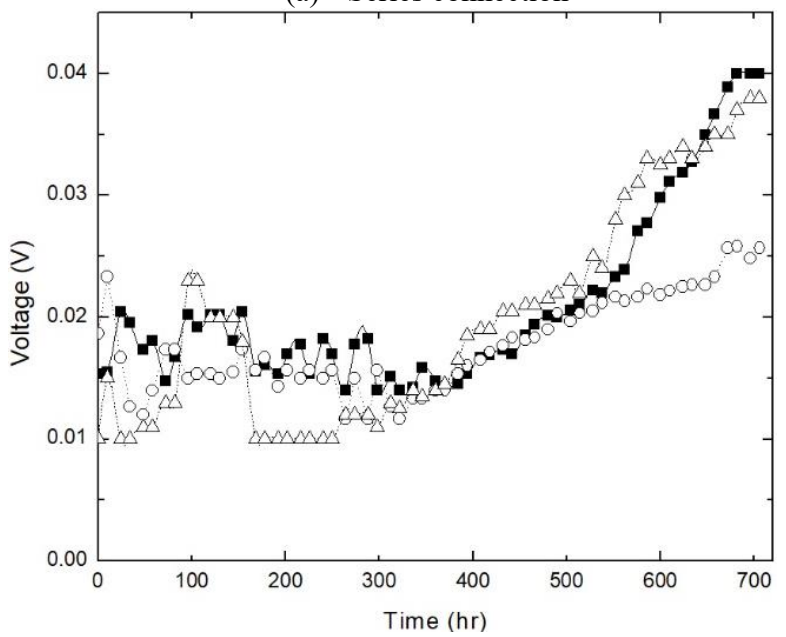

(b) Parallel connection

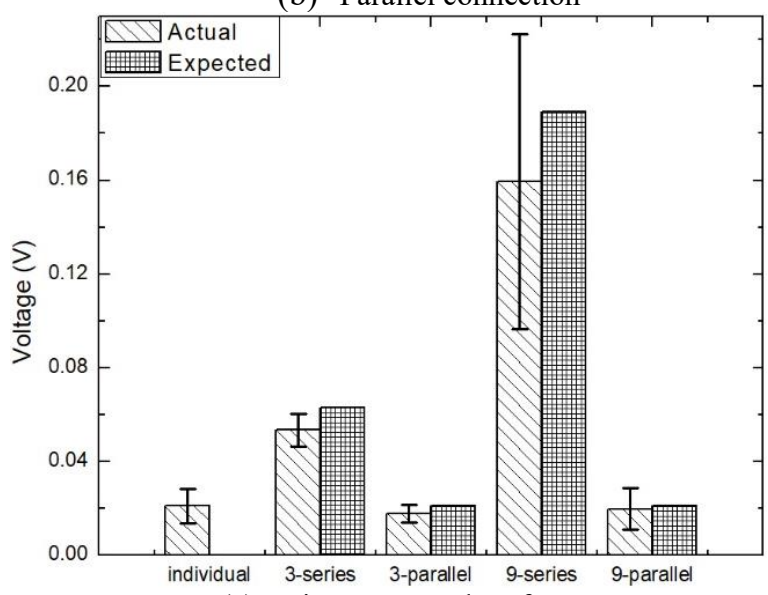

(c) Time-averaged performance

Fig. 3. Voltage comparison of individual ( $(\bullet)$ and stacked $[(\bullet)$ 3 cells in series; (०) 3 cells in parallel; $(\boldsymbol{\Delta}) 9$ cells in series; $(\Delta) 9$ cells in parallel] PMFCs growing $O$. basilicum
For cells connected in parallel (Figures $3 b$ and $4 b$ ), there is no significant difference between the voltages of multiple cells to the voltage of an individual cell $(\alpha=0.05)$. In the case of individual cells with differing voltages, their voltage when connected in parallel closely matches the average voltage of the individual cells. This behaviour is advantageous in situations wherein current needs to be amplified, or when voltage loss is to be avoided [7].

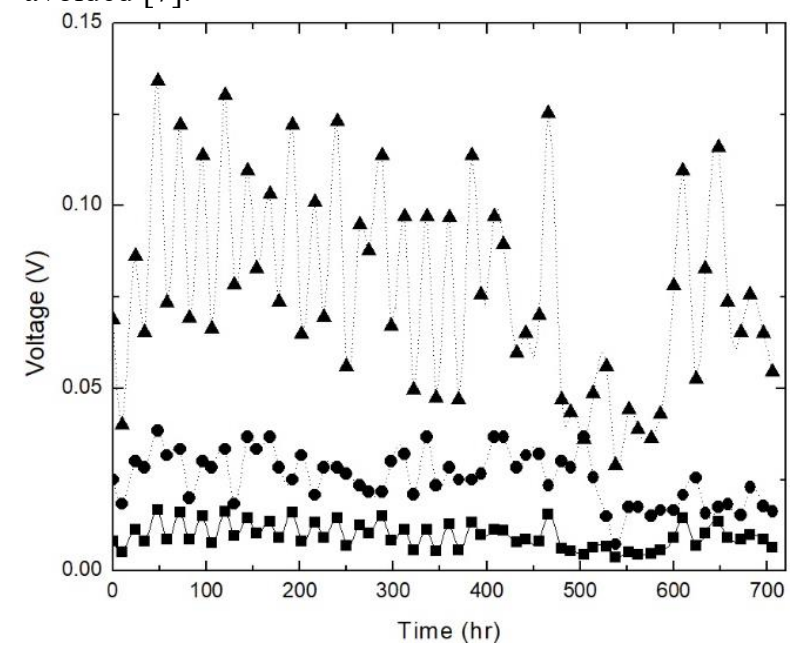

(a) Series connection

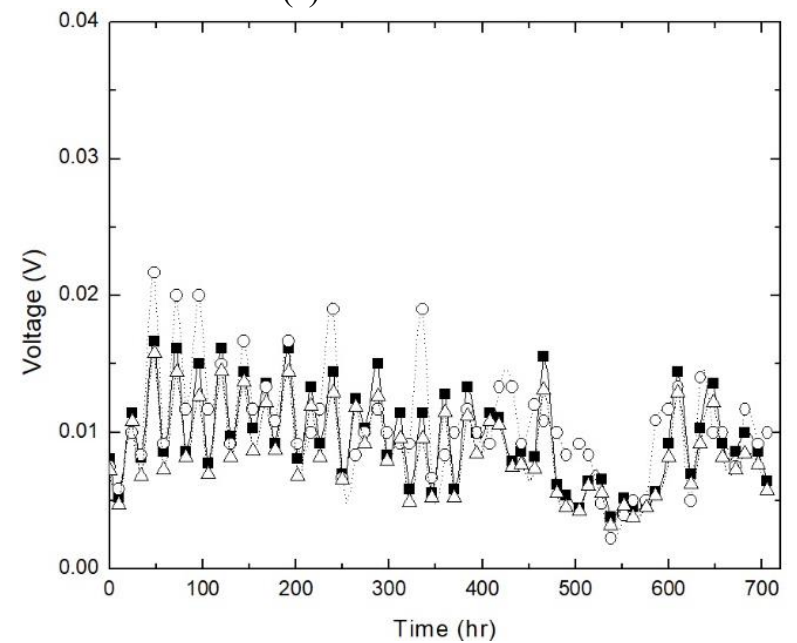

(b) Parallel connection

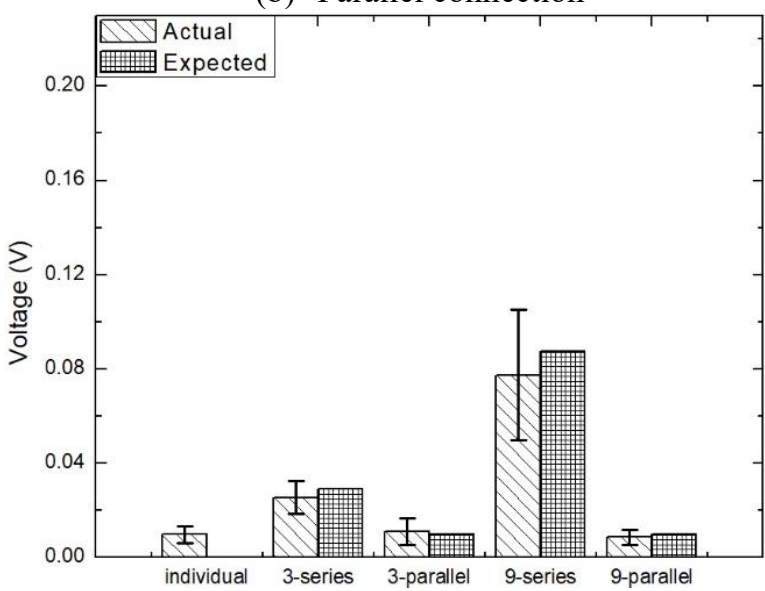

(c) Time-averaged performance

Fig. 4. Voltage comparison of individual ( $(\mathbf{)})$ and stacked $[(\bullet) 3$ cells in series; $(\circ) 3$ cells in parallel; $(\boldsymbol{\Delta}) 9$ cells in series; $(\Delta) 9$ cells in parallel] PMFCs growing $O$. vulgare 
If time-averaged voltages are to be compared, the performance of the constructed cells are shown in Figure $3 \mathrm{c}$ and $4 \mathrm{c}$. The actual voltage measured from 3 cells connected in series seems to be lower than the expected voltage, which is three times that of an individual cell. The same can be said for 9 cells connected in series. However, further statistical analysis revealed that there is no significant difference between the actual and expected voltage readings of all stacking combinations studies, within a $95 \%$ confidence interval. All of these results suggest that with further development, stacking may be used to create a vast network of PMFCs applied in fields to generate a significant amount of electricity. However, the extension of connections to beyond 9 cells must be carefully reviewed as it may induce voltage reversals which could produce severe voltage losses.

\subsection{Effect of cumulative stacking on voltage, power, and power density}

Cumulative stacking is a useful tool for determining potential loss over multiple cells connected in series or parallel. It compares the actual voltage registered upon adding cells one by one to the theoretical voltage. Technically speaking, the point at which the curve representing the actual voltage intersects with the line representing theoretical values is the optimum number of cells to be connected in series without appreciable loss in potential. In the case of this study, however, an outlier point (at $x=3$ cells) prevented such interpretation of the graph (Figure 5). However, majority of the points are lying above the theoretical line, meaning that there is no loss of potential for up to 9 cells connected in series and parallel. To further investigate, more cells should be constructed.

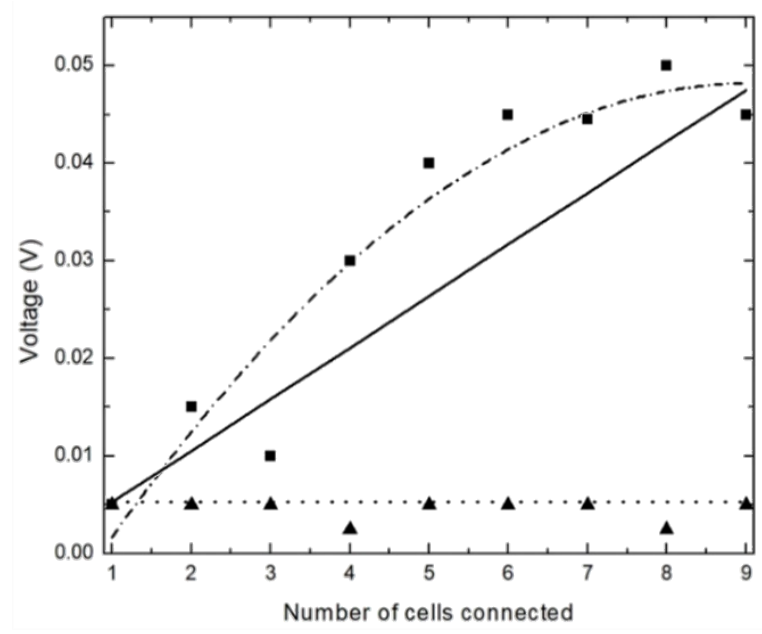

Fig. 5. Variation of voltage output with cumulative stacking: $(\boldsymbol{\square})$ series and $(\boldsymbol{\Delta})$ parallel; solid line represents theoretical voltage for series, while dotted line is the theoretical voltage for parallel. Dash-and-dot line represents a quadratic fit representation of series connection.

Both power and power density were observed to continually increase as more cells are connected in series but is seen to reach a plateau wherein both remain fairly constant (Figure 6). The trade-off between power and power density was observed in a batch microbial fuel cell (MFC), wherein power increases while power density decreases as the total surface area of the electrodes were increased. The intersection between the two curves represent the optimum electrode surface area in relation to the reactor volume to prevent large ohmic losses [12]. This phenomenon is a disadvantage for MFCs especially for larger scales because of the nature of its operation, wherein the nutrients needed by electrogenic bacteria are in limited quantities (batch operation). However, a separate study indicated that proper design considerations can lead to both increasing in MFCs [13]. In PMFCs, the stacked behavior contrasts that of MFCs. The plant continuously provides rhizodeposits for electrogenic bacteria in its roots, thereby power density is still observed to increase even if several cells are stacked together. These results are in accordance to compartmentalization effects in PMFCs [14].

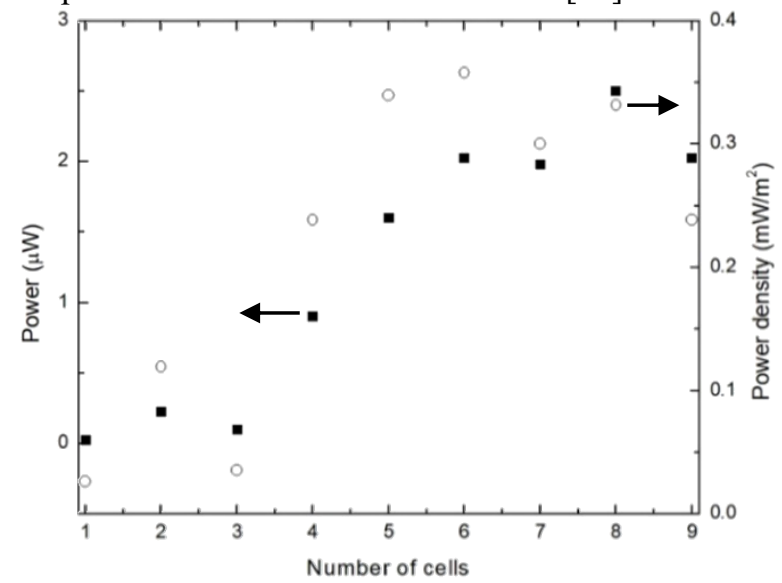

Fig. 6. Behaviour of power and power density in response to cumulative stacking for $O$. vulgare [( $\mathbf{\square})$ power; $(\circ)$ power density]

\subsection{Polarization}

The polarization curve of an individual PMFC and that of three cells connected in series is shown on Figure 7.

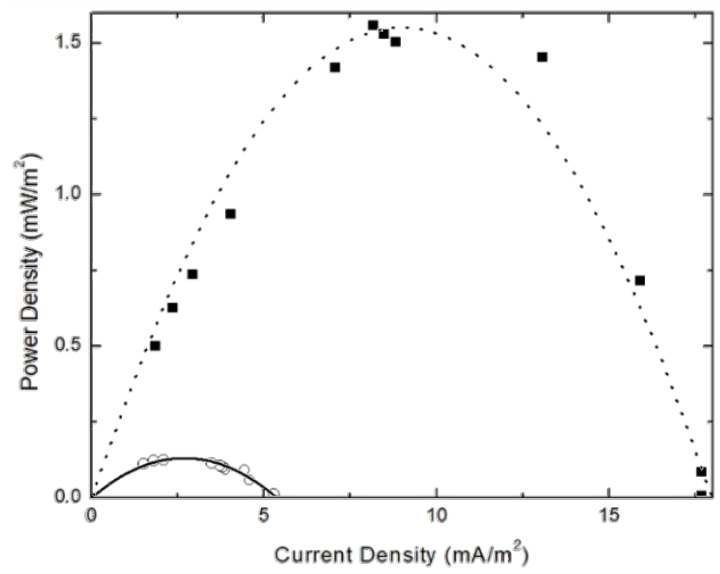

Fig. 7. Polarization curves of PMFCs growing $O$. vulgare connected in series ( $\square)$ compared to an individual cell $(\circ)$. 
Lines are fitted equations (solid line for individual and dotted line for series).

The series connection of cells exhibited a significant increase in maximum power density $\left(0.132 \mathrm{~mW} / \mathrm{m}^{2}\right.$ for an individual cell versus $1.57 \mathrm{~mW} / \mathrm{m}^{2}$ for three cells connected in series). The maximum point in a polarization curve also indicates the internal resistance exhibited by the system [3]. It was revealed that the power density drastically decreases at higher external resistances applied to the system. The internal resistance of an individual cell was determined to be about 20000 ohms compared to the $6800 \mathrm{ohms}$ for a stacked system. Stacking seems to lower the total internal resistance, presumably by providing more avenues for electrons to flow instead of a single path for an individual cell. The lower internal resistance of the cells connected in series allowed it to have a higher power density.

\section{Conclusions}

This study aimed to determine the stacking behaviour of PMFCs. Being biochemical systems, their electrical properties and behaviour are somewhat different from standard electrical components. The constructed PMFCs appear to obey the rules of stacking for voltage within experimental error: the voltage of cells connected in series is additive while the voltage of cells connected in parallel are averaged. Furthermore, cumulative stacking of cells either in series or parallel did not indicate any loss in potential.

Stacking cells appeared to increase both power and power density as the number of connected cells increased. This result is more advantageous than the behavior of MFCs. This means that the reported power density of PMFCs are generalizable for larger values of surface area. Furthermore, stacked cells have lower internal resistances than individual cells, which allowed them to register a higher power density. Overall, stacking remains a promising tool for the scale-up of PMFCs to deliver significant amounts of electricity simultaneous with food production. For future studies, more cells needed to be considered to further analyze the effects of stacking on larger systems.

The authors are grateful to Mapua University for funding the publication of this study.

\section{References}

1. K. R. S. Pamintuan, A. J. S. Gonzales, B. M. M. Estefanio, and B. L. S. Bartolo, "Simultaneous phytoremediation of $\mathrm{Ni2}+$ and bioelectricity generation in a plant-microbial fuel cell assembly using water hyacinth ( Eichhornia crassipes )," IOP Conf. Ser. Earth Environ. Sci., vol. 191, p. 012093, 2018.

2. P. Chiranjeevi, G. Mohanakrishna, and S. Venkata Mohan, "Rhizosphere mediated electrogenesis with the function of anode placement for harnessing bioenergy through CO2sequestration," Bioresour. Technol., vol. 124, pp. 364-370, 2012.
3. G. N. Nikhil, D. N. S. Krishna Chaitanya, S. Srikanth, Y. V. Swamy, and S. Venkata Mohan, "Applied resistance for power generation and energy distribution in microbial fuel cells with rationale for maximum power point," Chem. Eng. J., vol. 335, no. May 2017, pp. 267-274, 2018.

4. M. Helder, "Design criteria for the Plant-Microbial Fuel Cell Electricity generation with living plants from lab to application," 2012.

5. R. A. Timmers, D. P. B. T. B. Strik, H. V. M. Hamelers, and C. J. N. Buisman, "Electricity generation by a novel design tubular plant microbial fuel cell," Biomass and Bioenergy, vol. 51, pp. 6067, 2013.

6. R. Nitisoravut and R. Regmi, "Plant microbial fuel cells: A promising biosystems engineering," Renew. Sustain. Energy Rev., vol. 76, no. March, pp. 81-89, 2017.

7. K. R. S. Pamintuan, J. A. A. Clomera, K. V. Garcia, G. R. Ravara, and E. J. G. Salamat, "Stacking of aquatic plant-microbial fuel cells growing water spinach (Ipomoea aquatica) and water lettuce (Pistia stratiotes)," IOP Conf. Ser. Earth Environ. Sci., vol. 191, p. 012054, 2018.

8. L. Zhang, J. Li, X. Zhu, D. ding Ye, Q. Fu, and Q. Liao, "Response of stacked microbial fuel cells with serpentine flow fields to variable operating conditions," Int. J. Hydrogen Energy, vol. 42, no. 45, pp. 27641-27648, 2017.

9. H. Liu, B. Zhang, Y. Liu, Z. Wang, and L. Hao, "Continuous bioelectricity generation with simultaneous sulfide and organics removals in an anaerobic baffled stacking microbial fuel cell," Int. J. Hydrogen Energy, vol. 40, no. 25, pp. 8128-8136, 2015.

10. I. A. Ieropoulos, J. Greenman, and C. Melhuish, "Miniature microbial fuel cells and stacks for urine utilisation," Int. J. Hydrogen Energy, vol. 38, no. 1, pp. 492-496, 2013.

11. Y. Kuzyakov, "Review: Factors affecting rhizosphere priming effects," J. Plant Nutr. Soil Sci. Fur Pflanzenernahrung Und Bodenkd., vol. 165, no. 4, pp. 382-396, 2002.

12. J. Zhang, J. Li, D. Ye, X. Zhu, Q. Liao, and B. Zhang, "Tubular bamboo charcoal for anode in microbial fuel cells," J. Power Sources, vol. 272, pp. 277-282, 2014.

13. K. R. S. Pamintuan, I. H. P. Bagumba, and Z. D. G. Domingo, "Compartmentalization studies of a deepdesign batch Microbial Fuel Cell assembly," J. Phys. Conf. Ser., vol. 1457, no. 1, 2020.

14. K. R. S. Pamintuan, C. S. A. Reyes, and D. O. O. Lat, "Compartmentalization and polarization studies of a Plant-Microbial Fuel Cell assembly with Cynodon dactylon," Int. J. Smart Grid Clean Energy, pp. 720725, 2018. 